RURAL SUSTAINABILITY RESEARCH 46(341), 2021

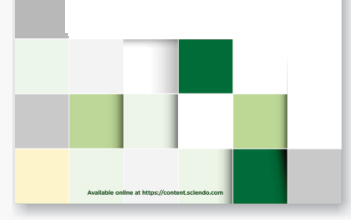

\title{
The Significance of "Green" Skills and Competencies Making the Transition Towards the "Greener" Economy
}

\author{
Jelena Nikolajenko - Skarbalė, *Rasa Viederytė, Agnẻ Šneiderienė \\ Klaipeda University, 84 Herkus Mantas street, Klaipeda
}

\begin{abstract}
Climate change and environmental deterioration have been recognized as global drivers of change, and the shift to the "greener" economy is the key to sustainable development. The green economy is a priority field for developing and developed economies. However, as the authors of the publication have realised, there is no consensus about the meaning of the green economy and "green" jobs, that is why an uncertainty as in measurement of economic trends and an impact of it, as well as in what skills and competencies should be assigned to the "green" ones, arises. The new "green" processes and technologies are arising in a progressive trend, that is why it is important to ensure there are properly skilled candidates with appropriate "green" skills and competencies on the labour market, as well as to prepare fresh graduates with the "green" skills that will meet requirement of both, the recent and the future companies, especially operating in the "green" sector. In the framework of "SB Bridge" project an online survey was conducted by interviewing the "green" companies to identify which skills and competencies are needed for "green" jobs recently, and whether candidates and fresh graduates are enough with the "green" skills and competencies for fruitful engagement to "green" jobs. As the survey identified, fresh graduates and candidates for "green" jobs lack technical and (or) mechanical knowledge, IT skills, as well as experience and ability to work independently and in the team to resolve arising problems.
\end{abstract}

Keywords: green economy, green skills, green competencies, green jobs, sustainable development.

\section{Introduction}

Globalization, increase of human's population and shortage of natural mineral resources, climate and technological changes, and other drivers have a strong impact on the demand for skills and competencies, particularly in the green and the blue sectors. Making the transition towards a "greener" economy, opportunities for the introduction of new clean technologies, "green" investments and "green" jobs are creating (International Labour Organization, 2018).

The long-term goal of the 2015 Paris Agreement is to keep the increase in global average temperature to less than $2^{\circ} \mathrm{C}$ above pre-industrial levels. The Agreement aims to help countries to meet this target and strengthen societies' capacities to address the wide-ranging impacts of climate change. It is planned that the transition to green economy will inevitably cause job losses in carbon-intensive and resourceintensive industries, but will create new job opportunities in other sectors (International Labour Organization, 2018). For instance, according to Eurostat (2020c), environmental protection activities (i.e. wastewater management, waste management) accounted for more than $78 \%$ of the employment in the environmental economy in 2000, the share decreased to $62 \%$ in 2017 following the creation of new jobs related to renewables and energy-efficiency. International Labour Organization (2018) argues that measures taken in the production and use of energy will lead to job losses of around 6 million as well as the creation of some 24 million jobs. The net increase of approximately 18 million jobs across the world will be the result of the adoption of sustainable practices, including changes in the energy mix, the projected growth in the use of electric vehicles, and increases in energy efficiency in existing and future buildings. In order to ensure the right and well-considered transition, efforts to promote the "green" economy must be accompanied by special policies that facilitate the reallocation of workers, offer local solutions and support displaced workers, as well as by redesigning the up-to-date high education and training system to provide necessary skills for today's enterprises working in the "green" economy, as well as meet the demands of tomorrow labour market.

Skills mismatch on the labour market results in high costs 
for individuals, enterprises, industries, economies and societies, and contributes to unemployment, lower returns on investments into training, decreased productivity and lost investment and job creation opportunities (Gregg, StrietskaIlina \& Büdke, 2015). That is why identifying and providing right skills for new, existing and forthcoming "green" jobs can smooth transition to the "greener" economy, and will help to tap into the vast employment potential and ensure that new opportunities benefit a broader share of society. Moreover, different countries moving towards "greener" economy face with different range of challenges depending on the historical level of economy, level of natural resources and climate conditions, and even on mindset and awareness of native citizens about the importance moving towards the "greener" future. That could mean that the demand of "green" skills and competencies sets in different countries will differ.

\section{Peculiarities of MSMEs moving towards "greener" future}

According to International Labour Organization (2018), most green economy's research, attention and initiatives focus on large corporations. This attention is understandable, as the "green" actions of few large enterprises in reducing of emissions are felt and reached more rapidly instead of few of MSMEs. However, according to International Energy Agency (2015), micro, small and medium-sized enterprises (MSMEs) are a central part of economies worldwide, accounted for over 90 per cent of enterprises throughout the world and providing about 60\% of employment. It is estimated that MSMEs use more than $13 \%$ of global total final energy demand, and, although their individual energy consumption, emissions and environmental impact may be small, their collective impact is considerable. MSMEs are slower with the adaptation of environmentally sustainable processes to shift to the production of "green" goods and services. The International Energy Agency (2015) emphasizes that MSMEs are particularly relevant to advance environmental sustainability with relatively little or even no investment.

The engagement of MSMEs with environmental sustainability is limited by the additional costs, lower awareness as of MSMEs representatives, as of the native customers that are not interested in a "greener" environmental impact (Aykol \& Leonidou, 2015). According to Johnson and Schaltegger (2016), unfortunately, even if sustainable management tools exist for MSMEs, they are rarely taken up. Hoogendoorn, Guerra and Van der Zwan (2015) argue that the ability to grow and to adopt environmental practices for MSMEs is usually limited by lower access to finance, compared with larger firms. Another limitation for MSMEs is informality, by excluding their workers from training and skills development programmes and (or) from public incentives (such as subsidies to adopt energy efficiency) (International Labour Organization, 2018).

\section{The green economy-uncertainty of the concept}

The green and (or) the blue economy; "green" jobs and (or) growth; resource efficiency and (or) environmental sustainability; ecosystem resilience; ecological and (or) environmental economics - all these topics, heard very often, are identified as priority for politics globally. However, there is a debate what the green economy is exactly about, what sub-fields this economy depends on and associated with, and how to measure its economic indicators to analyse what direction it is mowing to. Sometimes it is heard that green economy is just a buzzword, it is closely related (covers) to environmental economics, but has more politically applied focus, while environmental economics, with more arose focus on it only in XXI century, is a field of academic research as well as a sub-field of overall economics concerned with environmental issues.

European Environment Agency (2018) argues that the term "green economy" was coined in the late 1980s based on the reflection that environmental protection cannot be achieved unless an environmental perspective is integrated into economic and sectoral policies. Eco-union, MIOECSDE, GEC \& MAVA Foundation (2016) in their report consider that there is no global and standardized definition for green economy, while International Labour Organization (2018), by analysing green economy, is more focused on environmental economics' subfields and its statistics.

According to the European Centre for the Development of Vocational Training (2019) report, "green" term (i.e. jobs, skills, economy) is perceived and categorised differently in Europe. These different understandings make it difficult to compare patterns and trends between countries and to make general observations. For instance, in Denmark the green economy, with major activities in wastewater management, renewable energy resources, is defined as economy covering goods and services produced in order either to protect the environment or to save resources, and, respectively, "green" employment covers jobs that involved in the production of goods and services contributing to resource conservation, environmental protection, recycling, sustainable use of nature or similar purposes. There is still no unified approach in Estonia what a "green" job is and whether it is possible to define "green" skills as a separate competence.

The United Nations Environment Programme (UNEP) (2011) defines green economy as economy that results in improved human well-being and social equity, while significantly reducing environmental risks and ecological scarcities. In this type of economy, growth of revenue and of employment come from private and public investments that reduce pollution and carbon emissions, enhance the rational use of resources and prevent loss of biodiversity and environmental services. According to UNEP (2011), sectors considered to be driving the defining trends of the transition to a green economy, are: waste, manufacturing, energy supply, industry, water, buildings, fisheries, tourism, transport, forestry, water.

The European Commission (2011) considers a green economy as the one that generates growth, creates jobs and eradicates poverty by investing in and preserving the natural capital upon which the long-term survival of our planet depends. The EU (Eurostat, 2020c), the same as UNEP (2011) and International Labour Organization (2018), is analysing "green" trends by given statistics on environmental economics, that is divided into two main groups of activities:

(a) Environmental protection activities (according to CEPA (Eurostat, 2020a) - that is, preventing, reducing and eliminating pollution or any other degradation of the environment (i.e. wastewater management, waste management, other environmental protection activities), and

(b) Resource management activities (according to CReMA (Eurostat, 2020b) - that is, preserving natural resources and safeguarding them against depletion (i.e. water saving, renewable energy, energy efficiency).

The importance of green economy is undeniable. In 2019, 
The London Stock Exchange (2019) launched the Green Economy Mark and started to mark listed companies and investment funds on all segments with $50 \%$ or more of revenues from environmental solutions, i.e. that derive $50 \%$ or more of their total annual revenues from products and services that contribute to the global green economy.

3. The growing impact and created value by the green economy

In this sub-charter the authors of the publication are analysing the green economy's trends by environmental economics' sub-fields and their economic indicators, as performed by other organizations (Eurostat, 2020c; UNEP, 2011; International Labour Organization, 2018).

According to Eurostat (2020c), employment and gross value of environmental economy between 2000 and 2017 grew faster than in the overall economy. Employment in the EU-27 environmental economy increased from 3.1 million full-time equivalents in 2000 to 4.2 million full-time equivalents in 2017. The environmental economy generated EUR 698 billion output and EUR 287 billion gross value added (GVA) in 2017 (Eurostat, 2020c) (Figure 1).

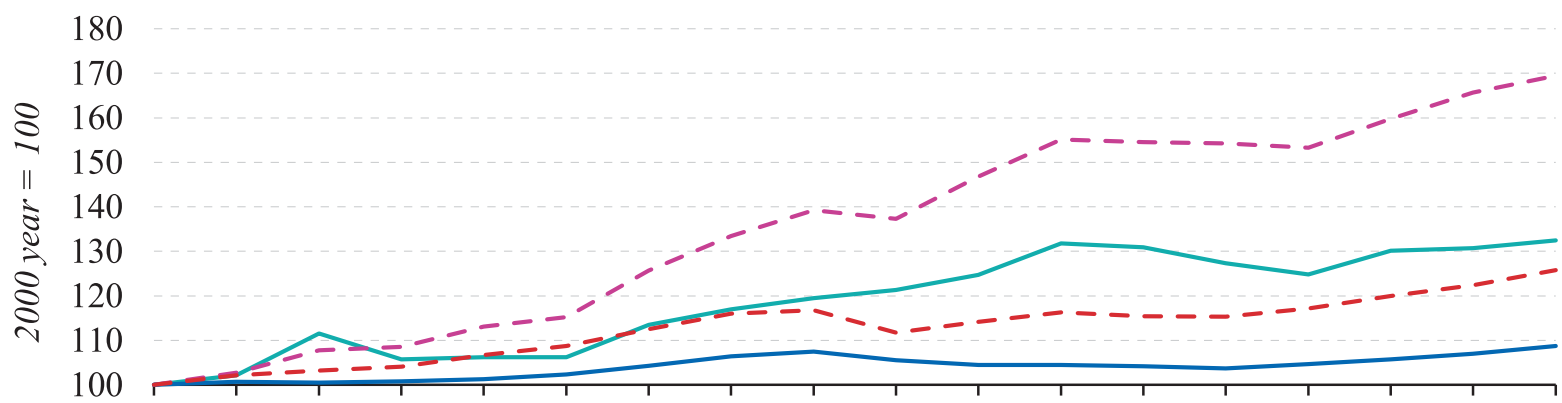

200020012002200320042005200620072008200920102011201220132014201520162017

Environmental economy: employment (') $\left(^{2}\right)$
Overall economy: employment

-- Environmental economy: gross value added (') $\left(^{3}\right)$

- - Overall economy: gross domestic product $\left({ }^{3}\right)$

( $\left.{ }^{1}\right)$ Eurostat estimates for Environmental economy: employment and Environmental economy: gross value added

$\left({ }^{2}\right)$ In full-time equivalents.

(3) Index compiled for chain-linked volumes data in EUR million (reference year 2010; at 2010 exchange rates) for Environmental economy: gross value added and Overall economy: gross domestic product

Figure 1. Development of key indicators for the environmental economy and the overall economy, EU-27, 2000-2017 (2000 = 100) (Eurostat, 2020c).

From 2000 to 2017, the environmental economy has outperformed the overall economy in terms of GVA and employment rates. When in 2009 the financial crisis caused a $4 \%$ reduction of overall economy's GDP, GVA from the production of environmental goods and services remained relatively stable and showed a constant growth till 2011, then remained stable up to 2014 and since 2014 to 2017 showed a strong, average 4\% growth, annually. According to Eurostat (2020c), from 2000 to 2017, it was a period of constant job creation in the environmental economy with temporary declining and then enhancing in its rates with estimated average $2 \%$ on an annual basis .

Green jobs are jobs that have a positive impact on the environment. The condition is that the people employed in them are directly or indirectly involved in improving the state of the natural environment. These can be described twodimensionally - as product and process. In the product dimension, they are jobs that involve manufacturing products and (or) providing services that directly contribute to environmental protection. They are created by companies from the "green" sector, e.g. a company producing photovoltaic panels, a company dealing with thermomodernization of buildings. In the process dimension, on the other hand, they are related to the broadly understood functioning of the company. Green jobs are those where employees perform tasks that contribute to reducing the negative impact of the company on the environment (e.g. a quality department employee, an employee who segregates waste, logistician who optimizes the supply chain). In this sense, those can also be created by a company outside the "green" sector, but with a strong focus on environmental protection. A good example here could be a company producing plastic packaging, which recycles materials, segregates waste, uses renewable energy sources, etc.

As it was mentioned before, employment in the environmental economy is represented by (Eurostat, 2020b): (a) environmental protection activities (i.e. wastewater management, waste management, other environmental protection activities), and (b) resource management activities (i.e. water saving, renewable energy, energy efficiency). As Figure 2 shows, employment in energy efficiency and renewable energy subsectors increased from 0.6 million fulltime equivalents in 2000 to 1.5 million full-time equivalents in 2017. According to Eurostat (2020c), almost one million new full-time equivalent jobs have been created in the EU-27 between 2000 and 2017 through renewables and energyefficiency measures. The second largest contribution to environmental employment, as Eurostat (2020c) emphasized, came from waste management, with the number of jobs increasing from 0.8 million full-time equivalents in 2000 to 1.2 million full-time equivalents in 2017 (overall increase of $38 \%)$. 


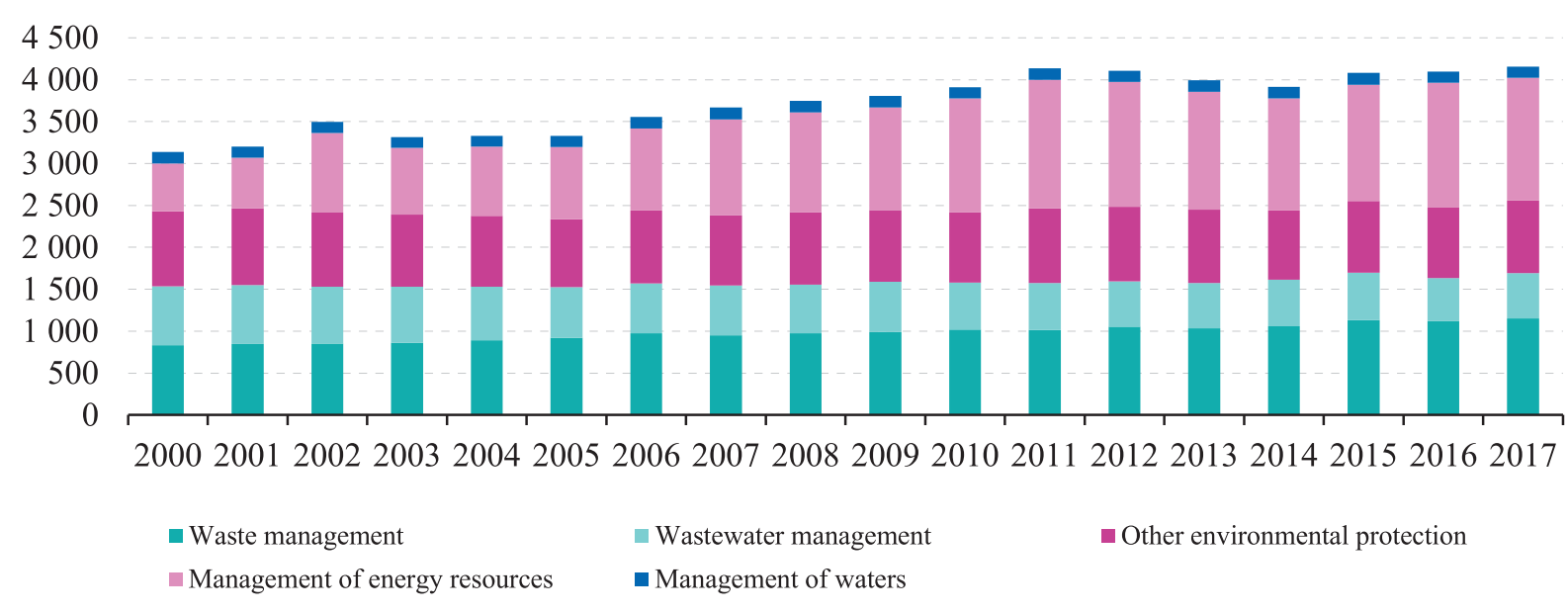

Figure 2. Employment in the environmental economy, by domain, EU-27, 2000-2017 (thousand full-time equivalents) (Eurostat, 2020c).

GVA of the environmental economy (including 5 subfields, mentioned in Figure 3) increased from EUR 130 billion in 2000 to EUR 287 billion in 2017 (Eurostat, 2020c) (Figure 3):

(a) GVA of environmental protection activities increased from EUR 99 billion in 2000 to EUR 166 billion in 2017 (contribution to GDP remained stable for the analysing period, i.e. from $1.2 \%$ in 2000 to $1.3 \%$ in 2017 ).

(b) GVA of resource management activities increased from EUR 31 billion in 2000 to EUR 121 billion in 2017, mostly due to growth of interest in the renewable energy sector (contribution to GDP remained stable for the analysing period, i.e. from $0.4 \%$ in 2000 to $0.9 \%$ in 2017).

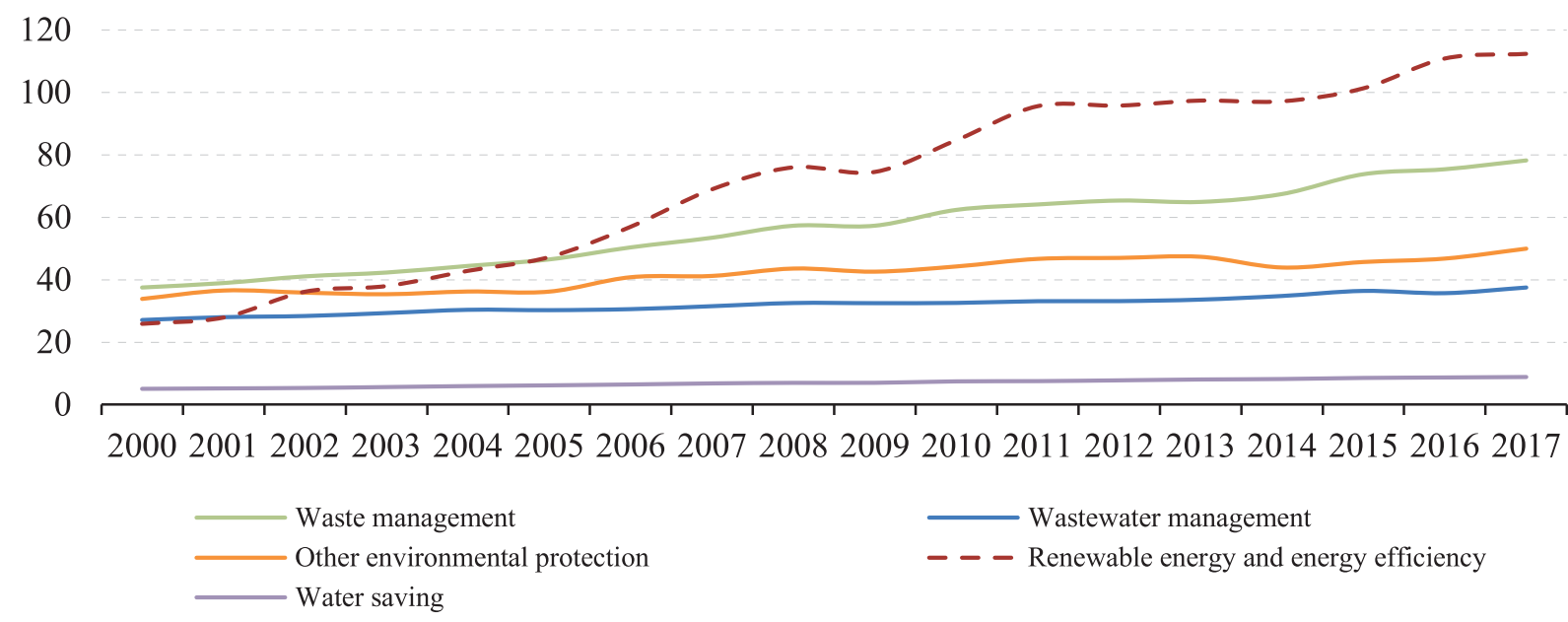

Figure 3. Gross value added of the environmental economy, by domain, EU-27, 2000-2017

(EUR billion) (Eurostat, 2020c).

4. Skills and competency: evolution of meaning and importance in "greening" the jobs

Human capital is the key factor for economic success of any organization, Skorkova (2016) argues. Every performing organization is linked with high performing people. Selecting talented employees, who are able to carry out the organization's vision, mission and meet the targets, is critical for every company (Skorkova, 2016). The question arises, what helps humans to maintain its position and even perform better than others? Do we talk about knowledge, skills, talent, experience? Everything is covered by competence.

According to Doyle (2020), there are "soft" and "hard" skills that are both important during the job or internship application. Hard skills are teachable abilities or skill sets that are easy to quantify, for example, technical, management, marketing, analytical, design, accountancy, etc. Typically, these skills a person is learning in the classroom, through books or other training materials, or on the job. Soft skills are the skills that enable a person to fit in at a workplace. Sometimes, these kinds of skills are difficult to quantify. They include human's personality, attitude, flexibility, motivation, communication, creative and (or) critical thinking, work ethic and (or) problem resolution, and manners. Doyle (2020) argues, "soft" skills are so important that they are often the reason employers decide whether to keep or promote an employee.

According to Skorkova (2016) competence can be described as the set of demonstrable characteristics and skills 
that enable and improve the efficiency or performance of a job. Skorkova (2016) argues, the word of "competence" comes from the Latin word "competent", which can be translated as "one who has the right to judge" or as "the one who has the right to speak".

There are three main phases of the evolution of competency meaning and understanding. The term "competence" first appeared in 1959, in an article authored by an American psychologist White (1959) as a concept for performance motivation. White has started the first era of competencies in HR management, that was typical for analysing of individual competencies (White, 1959; Boyatzis, 1982). The second phase of competencies in HR management is associated with scientists Mansfield (1996) and McLagan (1997) and was typical by generation of competency models in organizations. When in 1990 Prahalad and Hamel (1990) focused on and analysed the idea of core competencies, the third phase of competencies in HR management started, and was based on the idea that core competencies are strongly important for a person to gain a competitive advantage in the organisation (Prahalad \& Hamel, 1990; Delamare \& Wintertone, 2005).

Trivellasa and Reklitisb (2014) argue, that competencies acquired in education are necessary for individual effectiveness making first steps to the labour market, as well as for long-lasting employability, later. Allen, Ramaekers and Van der Velden (2005) proposed two main types of competencies: "general" and "specific". Specific competencies refer to the profession or field specific knowledge and skills (Trivellasa and Reklitisb, 2014), and are important to a person to be able to perform adequately in a given substantive domain (Weinert, 2001). General competencies include a diversity of concepts, such as intelligence, information-processing models, and key competencies, which may be exercised in a range of contexts and contents (Trivellasa and Reklitisb, 2014). A major advantage of this group, according to Trivellasa and Reklitisb (2014), is that general competencies facilitate the transfer of existing "specific" competencies and the acquisition of new competences which can be used in new work situations.

Abraham and his colleagues (2001) were generating an idea, that all organizational functions require a set of essential "managerial", "general" and "specific" competencies to perform effectively. The mentioned researchers considered that "managerial" competencies are important for supervisors or managers with supervisory responsibilities in any service. "General" competencies are important for all staff, regardless of their functions or level, and in order to perform any functions within the organization with a defined functional or (and) technical work field, the "specific" competencies are necessary.

For every economic sector and its sub-fields there are appropriate and relevant skills and competencies sets. To identify what skills and competencies are needed for "green" jobs recently and are demanded by up-to-date companies operating in the "green" sector, and whether candidates and fresh graduates are enough with the "green" skills and competencies for fruitful engagement to a "green" job, the survey was conducted.

\section{Materials and Methods}

The current paper applies a synthesis of two research methods:

(a) Theoretical research method for secondary data collec- tion, analysis, comparison, systematisation and generalization, to identify the enhancing importance of green economy and rapid changes in "green" skills and competencies requirements by "green" companies, and

(b) Quantitative research method, implemented by using standardized three section Questionnaire, to identify directly what "green" skills and competencies are needed for "green" jobs recently and whether the up-to-date fresh graduates and candidates are well skilled for fruitful engagement to the "green" jobs.

The survey was organized in the framework of the project "South Baltic Bridge - building bridges for the green technology future" (SB Bridge, 2021) by obtaining information on how to improve the mismatch between education and training systems and labour market needs, facilitate the transition from education to employment in the industry by strengthening VET systems and their quality, and create and (or) develop internship and (or) apprenticeship programs in the workplace.

The survey was conducted from the 2nd of December 2020 to the 5th of March 2021. As the "SB Bridge" project was implemented by 5 European countries (Lithuania, Poland, Sweden, Denmark and Germany), each partnercountry was required to provide a questionnaire to eligible companies, and a total of 450 micro, small, medium and large enterprises were invited to complete the Questionnaire. Due to the world situation at the time of survey as a result of the COVID-19 pandemic, the authors of the publication have encountered difficulties in contacting most companies whose activities were likely suspended or limited. Nevertheless, the 70 "green" economy representatives from 5 partnerscountries participated in the survey and represented the following environmental economics' sub-fields: renewable energy, waste management, water management, green building, clean transportation.

The standardized Questionnaire (Appendix 1) was sent to respondents directly by an e-mail, and contained multiplechoice, single-choice closed and open-ended questions, and consisted of three main sections:

(a) 1st section questions were related to the recruitment process "green" companies apply.

(b) 2nd section questions were related to "soft" and "hard" skills, "general" and "specific" competencies "green" companies expect and (or) require for the modern "green" jobs.

(C) 3rd section questions were related to whether companies operating in the "green" economy collaborate with universities and (or) vocational schools, by offering internship and (or) traineeship opportunities; and what skills are important to be gained during the education and what are teachable during the internship and (or) traineeship period in the "green" enterprise.

\section{Results and Discussion}

As can be seen from Figure 4, where it is shown the distribution of respondents by country, $43 \%$ of surveyed companies were operating in Germany, 21\% in Sweden, 14\% in Denmark, $11 \%$ in Lithuania and $10 \%$ were operating in Poland. 


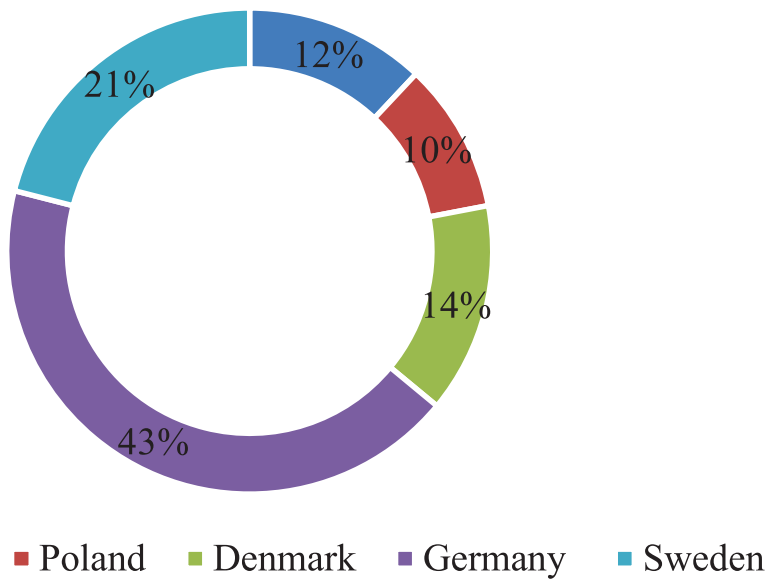

\section{- Lithuania $\square$ Poland $\square$ Denmark $\backsim$ Germany $\square$ Sweden}

Figure 4. Distribution of respondents by country, \%.

All of the surveyed companies, as there is shown in Figure 5 , were operating in the 5 main sub-fields of environmental economics: renewable energy (30\%, and the most), waste management (17\%), water management (23\%), green building (19\%) and clean transportation (11\%) sectors. In Denmark $(60 \%)$ and in Poland $(57 \%)$, most companies participating in the survey represented water management sector, in Sweden renewable energy sector $(40 \%)$, while in other countries surveyed companies covered more or less all sectors in equal parts.

Most companies (42\%) participating in the survey were

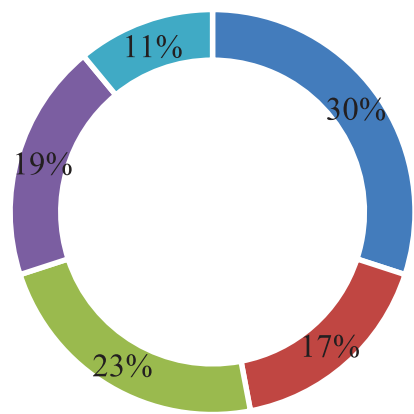

- Renewable energy

- Water management

- Clean transportation

Figure 5. Distribution of respondents by sector, \%.

Representatives of "green" enterprises were asked to indicate which field of study they are likely to hire graduates from for open "green" positions. The most desired fields of study were Engineering and Technology (80\% of respondents indicated), Sales and Marketing (43\%), System design and IT (39\%). Logistics and Economics (16\%) and Public administration (7\%) were indicated as the least desired fields of study for "green" jobs.

Companies operating in the "green" sector usually look for new employees via general online job banks $(76 \%$ of respondents indicated), through specialized agencies (24\%), or (and) the career offices at the university or (and) high school (11\%), or (and) internal company's database (10\%).

Representatives of the "green" companies were asked to small (less than 50 employees), 26\% were medium (less than 250 employees), $21 \%$ were micro (less than 10 employees), and $11 \%$ were large (more than 250 employees). According to mentioned distribution, there is domination of micro, small and medium-sized enterprises (MSMEs) in the survey that is equal to $89 \%$ totally (Figure 6). In Denmark (50\%) the majority of the surveyed companies were medium, in Germany (57\%) were small, while in Lithuania (50\%) and in Poland $(43 \%)$ the larger number of respondents were micro companies.

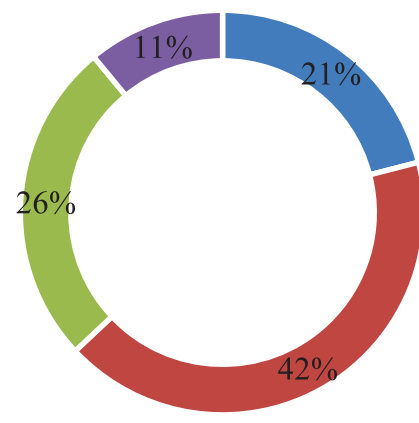

- Micro " Small - Medium - Large

Figure 6. Distribution of respondents by company size, $\%$.

identify what they prioritize when selecting a candidate for a position in their company. The distribution of priorities can be seen in Figure 7.

Practical experience is most valued by the hiring companies. Soft skills as ability to network and good communication $(71 \%)$, ability to put theoretical knowledge into practise $(66 \%)$ and ability to be flexible to market needs and changes $(51 \%)$ are important for the hiring "green" companies. Entrepreneurs added that creative mindset is a very important skill for the "green" job implementer. Hard skill as theoretical knowledge $(61 \%)$ that a person gains at educational institution is important for the surveyed companies in all countries. 


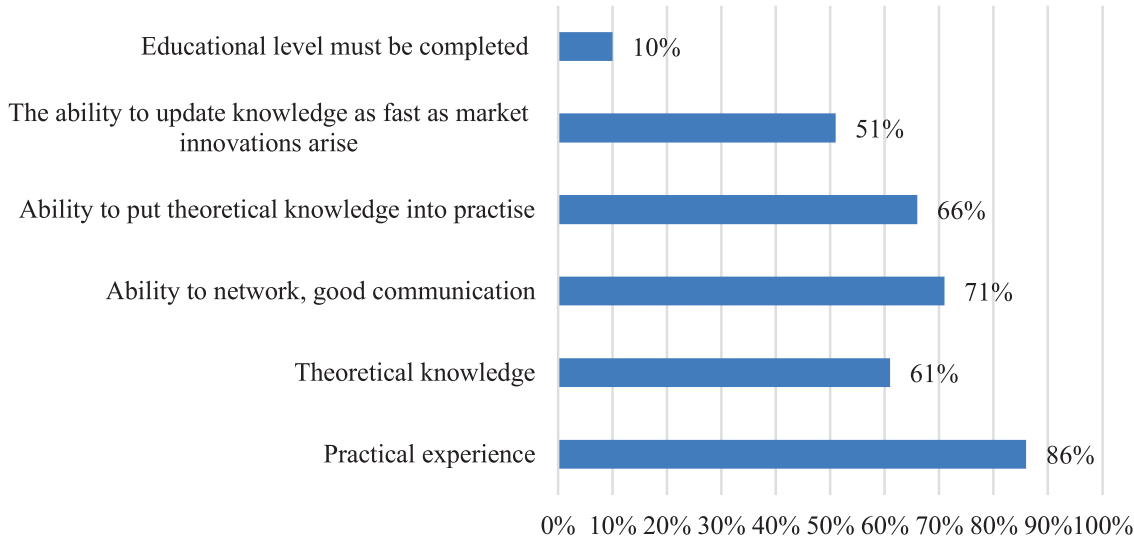

Figure 7. Priorities when selecting a candidate for a "green" job, $\%$.

Representatives of the surveyed companies were asked to specify which "hard" and "soft" skills fresh graduates lack when they apply for "green" jobs in their company (Figure 8; Figure 9).

As can be seen in Figure 8, the lack of technical and (or) mechanical know-how was indicated most often. Absence of some theoretical knowledge especially important in preparation of technical drawings and (or) in the construction

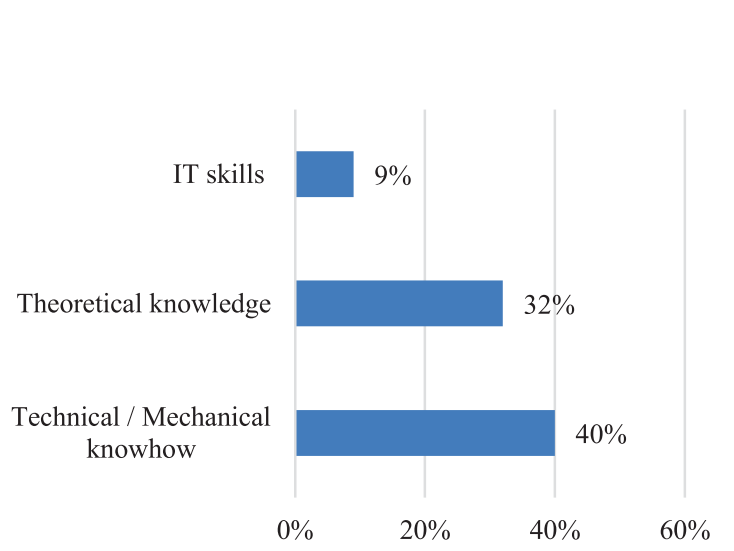

Figure 8. Hard skills that fresh graduates are lacking when they apply for a "green" job, $\%$.

The distribution of possibilities for students of an internship and (or) a traineeship within "green" companies and the level of education is needed for interns and (or) trainees is shown in Figure 10 and Figure 11.

$53 \%$ of the "green" companies are offering internship and (or) traineeship possibilities for students. Most often internships and (or) traineeships are offered in Denmark $(80 \%)$ and in Lithuania (88\%), the least - in Poland (29\%) process, and insufficient knowledge of project management, were also identified by representatives of "green" enterprises as a gap for fresh graduates.

As for the "soft" skills (Figure 9), fresh graduates are lacking the ability to work independently, to design and to implement a solution to the arisen problem (problem-solving skills). Fresh graduates have difficulties with critical thinking and integration into the company's culture.

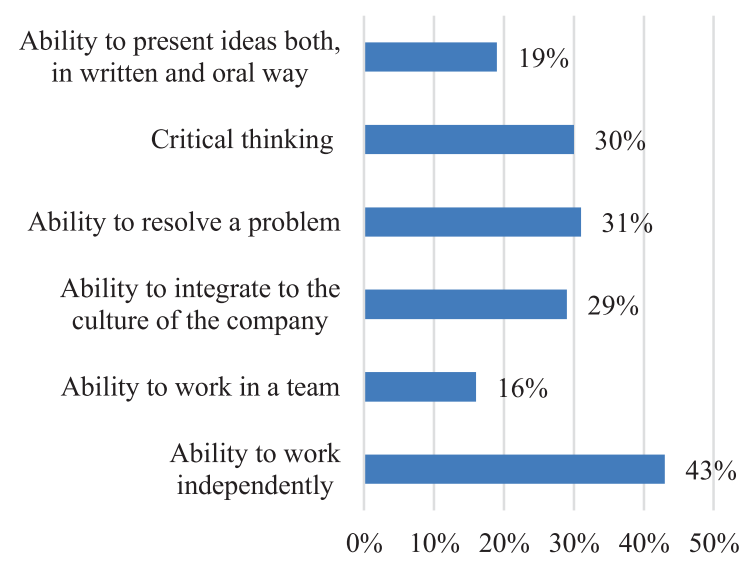

Figure 9. Soft skills that fresh graduates are lacking when they apply for a "green" job, \%.

(Figure 10).

As can be seen in Figure 11, 44\% of respondents indicated that students from the university are most preferred for an internship and (or) a traineeship, while $26 \%$ of surveyed entrepreneurs mentioned vocational schools' graduates as appropriate for an internship and (or) a traineeship in their company.

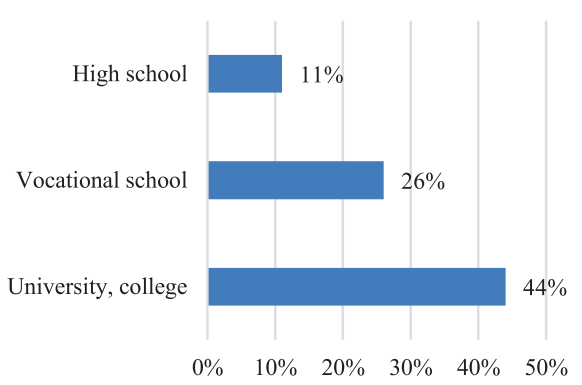

Figure 10. Distribution by an internship and (or) traineeship offers in "green" companies, \%.
Figure 11. Level of education needed for interns and (or) trainees in "green" companies, \%. 
The respondents were asked to specify which skills and competencies they wish to develop by offering an internship and (or) a traineeship (Figure 12). As can be seen from Figure 12, "green" companies are willing to help students to develop practical experience and ability to apply theoretical knowledge skills (46\%) during an internship and (or) a traineeship. Ability to work and to generate decisions both, independently and being in a team, is very often developed during an internship and (or) a traineeship. Additionally, $84 \%$ of respondents pointed out that there is a possibility to be employed at the end of an internship and (or) a traineeship, and only $16 \%$ stated that such a possibility for interns and (or) trainees doesn't exist in their "green" company.

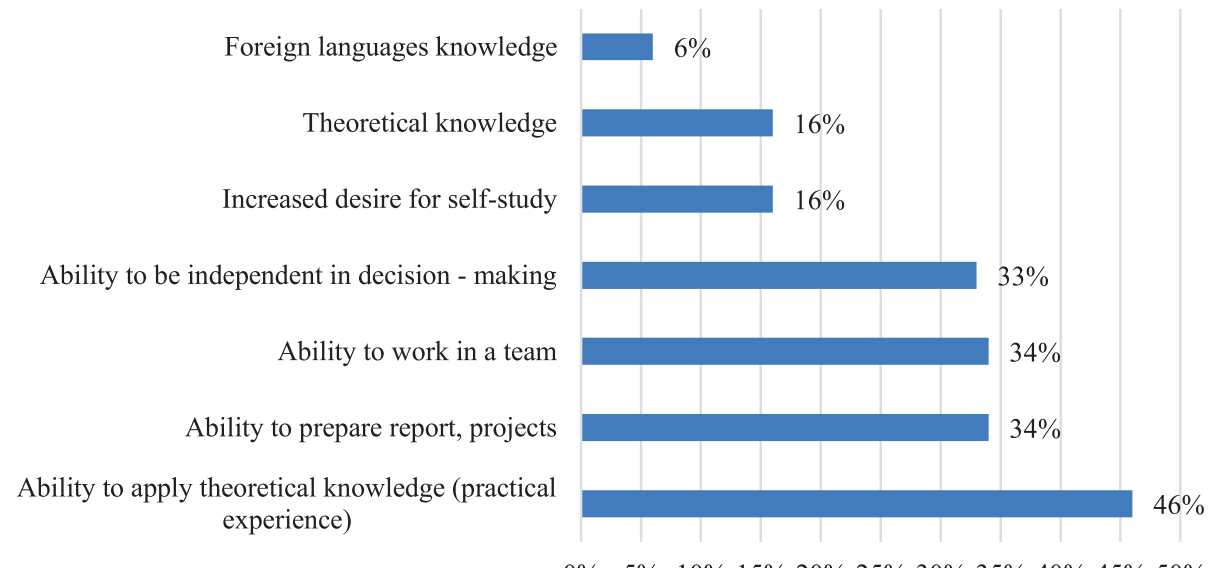

Figure 12. Skills and competencies developed during an internship and (or) a traineeship in the "green" companies, $\%$.

Green skills are often included in general, in existing skill sets. Taken together, "green" skills are generally composed of three dimensions: knowledge, skills, and attitudes (values). In addition to job-specific knowledge and skills, the following core qualifications are required for "green" jobs by "green" companies, the Survey identified:

(a) Strategic and leadership skills that enable political and economic decision-makers to set appropriate incentives and framework conditions for environmental protection, environmentally friendly transport, etc.

(b) Entrepreneurial and management competencies to be able to combine economic, ecological and social goals in holistic and interdisciplinary approaches.

(c) Adaptation and transfer competencies that enable workers to learn and apply new environmentally friendly technologies and processes relevant to the workplace.

(d) System and risk competencies to understand, implement and evaluate necessary change processes and measures.

(e) Innovation competence to respond adequately to green challenges.

(f) Communication and negotiation skills to manage conflicts of interest in complex contexts.

(g) Marketing skills to be able to launch environmentally friendly products and services.

(h) Consultancy skills to advise consumers on green solutions and disseminate green technologies.

(i) Entrepreneurial skills and abilities to seize the opportunities of low-carbon technologies.

(j) Environmental awareness and willingness to learn about sustainable development.

(k) Networking, ICT and language skills to be able to operate in global markets.

The conducted Survey showed that "green" enterprises suffer from systemic weaknesses in skills base of fresh graduates and candidates, what limits their productivity and competitiveness in today's economy, and reduce their capacity to exploit the opportunities offered by "green" growth. Skills are crucial for economies and businesses to adapt rapidly to changes. The adoption and dissemination of "green" technologies require skills in technology application, adaptation and maintenance. Skills development is a critical driver of change, stimulating "green" investment, technological and sustainable innovations into markets at competitive prices.

\section{Conclusions and Recommendations}

1. There is no consensus about the meaning of green economy and "green" jobs, that is why there is an uncertainty in measurement of economic trends and an impact of it. The only thing that is undeniable, is that the green economy is always about sustainable development. Different countries, moving towards "greener" economy, face with different range of challenges depending on the historical level of economy, level of natural resources and climate conditions, and even on a mindset and awareness of native citizens about the importance moving towards the "greener" future. That could mean that the demand of "green" skills and competencies sets in different countries will differ.

2. Based on the responses received during the Survey, it is difficult for the "green" companies to find well-skilled and qualified employees for key positions in their companies. However, with a relatively small scale of employee turnover, most "green" companies did not face this problem directly. In the opinion of the surveyed entrepreneurs, candidates with practical experience and soft skills, like good communication skills, ability to work independently and in a team, are most valued by "green" companies.

3. Lack of technical and (or) mechanical knowledge, 
as well as the lack of experience and ability to work independently to resolve arising problems and to improve existing ideas, the ability to adapt to the culture of the workplace, were indicated as a shortage for fresh graduates.

4. As the Survey indicated, there is a need to combine both, technical knowledge and business and management competencies in the green economy, as the green economy is based on technological innovations, which need to be understood in order to be effectively implemented and developed. Hence, an interdisciplinary approach to education is recommended, with the use of modular training. The "green" entrepreneurs' statements indicate significant gaps in the labour market in specialized knowledge related to the new technologies used in the green economy - this applies mainly to the energy-efficient construction and specialized consulting.

5. Considering rapidly changing requirements for "green" jobs, the need to combine education and business is emphasized, to "feel the pulse" of changes of requirements for "green" skills within the "green" sector and to prepare students both, for current and tomorrow companies' needs. Such an arrangement would make it easier for graduates to gain both, theoretical knowledge and practical experience required in the recruitment process. Most companies would be willing to offer the possibility of internships and (or) internships in their company, especially for university students. During internships and (or) internships, students would be able to apply theoretical knowledge and develop practical experience, analytical and reports writing skills, and decision-making skills as independently, as well as working in the team.

\title{
Analysis of the Desired Skills and Competencies Within the "Green" Sector
}

\author{
Questionnaire
}

This questionnaire is created by the "SB Bridge - building bridges for green-tech future" project. The project focuses on bridging students and the green and blue labour market, via: (1) reducing the mismatch between higher education and their graduates and the green and blue labour market, (2) improving motivation of young people for green and blue related studies and jobs. The project is jointly developed by partners from 5 Baltic Sea countries: Denmark, Germany, Lithuania, Sweden and Poland.

Your answers will help to prepare and guide students in the direction of a job in Your sector. We sincerely thank You for Your participation!

Choose your language:
English
Danish
Lithuanian
Polish
Swedish
German

1. The first questions relate to your recruitment process and the quality of the applicants you receive when hiring.

1.1 Please indicate your company size:

Micro-sized entrepreneur (less than 10 employees)

Small-sized entrepreneur (between 11 - 50 employees)

Medium-sized entrepreneur (between 51 - 250 employees)

Large-sized entrepreneur (more than 251 employees)

1.2 How do you recruit new employees?

Via general online job banks

Through the career offices at the university/school

Through specialised agencies

Internal company database

Other:

1.3 Please select a sector for a specific question regarding the demands for skills and competence in your sector:

Renewable energy

Waste management

Water management 
Green building

Clean transportation

2. These questions relate to your needs for specific competencies and skills when you are recruiting, and if you experience any shortcomings from fresh graduates. Your answers will help to guide and build bridges between the needs in your sector and the educational levels, so please feel free to be as specific as possible.

2.1 Which field of study are you most likely to hire from?

Engineering and Technology (Natural sciences at university level)

System design and IT

Public administration including law

Sales and marketing

Logistics and economics

Vocational training

Other

\subsection{What do you prioritize when selecting a candidate for a position in your company?}

Theoretical knowledge

Practical experience

Educational level must fit completely

Ability to put theoretical knowledge into practical solutions

Updated on trends and future demands and ability to apply that in the workplace

Soft skills like good communications skills, ability to network and adapt to the culture of the workplace

Other

2.3 Which hard skills do you experience fresh graduates lack when they apply for a job in your company?

Technical/mechanical knowhow, such as

Theoretical knowledge (including rules and regulation within your sector), such as

IT skills, such as

Other

2.4 Which soft skills do you experience the fresh graduates lack when applying for a job in your company?

Ability to work in a team

Ability to work independently

Ability to design and implement a solution (problem-solving)

Critical thinking and the ability to improve on existing ideas

Communicative skills like a foreign language or the ability to present cases both oral and in text

Networking capacity

Ability to adapt to the culture of the workplace

Other:

2.5 What do you consider the biggest challenge within your sector?

Inability to attract relevant knowhow

Lack of new ideas and adventurous research

Lack of technology/technological development

Lack of support from official/governmental site

The abundance of rules and regulation that must be applied when testing new materials/processes

Lack of financial support for "non-profit" solution

Lack of public demands for "greener" solutions

Other:

3. We have now gained much-needed knowledge of the recruitment process in your company/sector. We would also like to know ifyou offer other ways in your company/sector. 
3.1 Does your company offer students an internship/traineeship? If not please tell us the reason.

Yes

No, and the reason is

(Please go to the question no. 3.5)

3.2 Why do you offer internships?

3.3 At what level of education do you accept interns/trainees?

University

High schools

Vocational schools

Other:

3.4 Which skills and competencies do you wish to develop by offering an internship?

Theoretical knowledge

Practical experience and ability to apply theoretical knowledge

Teamwork skills

Ability to adapt to new conditions

Increase the desire for self-study

Independence in decision-making

Analytical skills and ability to produce reports/projects

Knowledge of foreign languages

Other:

3.5 During the internship can the student:

Test and/or apply their theoretical knowledge in practice

Test their ability to produce independent analyses, programs, classes, etc.

Participate in daily company life

Gain stress-free entry into the labour market

Other:

3.6 Is it possible to be employed at the end of the internship/practice?

Yes

No

3.7 We consider your knowledge very important and would like to hear your suggestions for improvements.

3.8 Do you notice educational deficiencies preventing students from being employed directly after graduation?

No

Yes, and they are:

3.9 How would you like to influence the curriculum of the educational system to meet the needs of your company for the skilled labourer?

3.10 How do you suggest we make students aware of the broad range of job opportunities that exist within your sector?

3.11 Dou have any further comment or suggestions you wish to share with the $S B$ Bridge project?

3.12 If you want to learn more about $S B$ Bridge project or take part in preparing students and graduates for a job within the blue/green economy, please fill in the following section:

Company name:

Name of contact person: 
Email:

\section{Thank You for participating!}

\section{References}

Abraham, S.E., Karns, L.A., Shaw, K. \& Mena, M.A. (2001). Managerial competencies and the managerial performance appraisal process. Journal of Management Development, 20 (10), 842-852.

Allen, J., Ramaekers, G., \& Van der Velden, R. (2005). Measuring Competencies of Higher Education Graduates. New Directions Institutional Research, 2005 (126), 49-59

Aykol, B., \& Leonidou, L.C. (2015). Researching the green practices of smaller service firms: A theoretical, methodological, and empirical assessment. Journal of Small Business Management, 53 (4), 1264-1288

Boyatzis, R.E. (1982). The Competent Manager: A model for Effective Performance. New York: John Wiley \& Sons.

Delamare Le Deist, F. \& Wintertone, J. (2005). What Is Competence? Human Resource Development International, 8(1), 27-46.

Doyle, A. (2020). Hard Skills vs. Soft Skills: What's the Difference? The Balance Careers. Retrieved June 318,2021 , from

https://www.thebalancecareers.com/hard-skills-vssoft-skills-2063780.

European Commission. (2011). Rio+20: towards the green economy and better governance. Communication from the Commission to the European Parliament, the Council, the European Economic and Social Committee and the Committee of the Regions. $\mathrm{COM} / 2011 / 363$

Eco-union, MIO-ECSDE, GEC \& MAVA Foundation. (2016). Towards a Green Economy in the Mediterranean. Assessment of National Green Economy and Sustainable Development Strategies in Mediterranean Countries.

European Centre for the Development of Vocational Training (CEDEFOP). (2019). Skills for green jobs. European synthesis report. Luxembourg: Publications Office of the European Union.

European Environment Agency (EEA). (2018). Environmental indicator report. Retrieved June 3-18, 2021, from https://www.eea.europa.eu/publications/environmen tal-indicator-report-2012/environmental-indicatorreport-2012-ecosystem/part1.xhtml.

Eurostat. (2020a, February). Classification of environmental protection activities (CEPA). Retrieved June 3-18, 2021, from https://ec.europa.eu/eurostat/statisticsplained/index.php?title=Glossary:Classification_of environmental_protection_activities_(CEPA).

Eurostat. (2020b, February). Classification of environmental protection activities (CEPA) and classification of resource management activities (CReMA).

Retrieved June 3-18, 2021, from

https://ec.europa.eu/eurostat/ramon/nomenclatures/i ndex.cfm? TargetUrl=LST_NOM DTL\&StrNom $=\mathrm{C}$ L CEPAREM\&StrLanguageCode $=$ EN\&IntPcKey $=$
$\&$ StrLayoutCode=HIERARCHIC .

Eurostat. (2020c, June). Environmental economy statistics on employment and growth. Retrieved June 3-18, 2021, from https://ec.europa.eu/eurostat/statisticsexplained/index.php?title=Environmental_economy $\% \mathrm{E} 2 \% 80 \% 93$ statistics on employment and gro wth\&oldid $=47 \overline{7} 477$ \#Employment by environmenta 1_domain.

Gregg, $\bar{C}$., Strietska-Ilina, O., \& Büdke, C. (2015). Anticipating skill needs for green jobs. A practical guide. Zeneva: International Labour Office.

Hoogendoorn, B., Guerra, D., \& Van der Zwan, P. (2015). What drives environmental practices of SMEs? Small Business Economics, 44 (4), 759-781

International Energy Agency (IEA). (2015). Accelerating energy efficiency in small and medium-sized enterprises: Powering SMEs to catalyse economic growth. Paris: OECD.

International Labour Organization. (2018). Greening with jobs. Word employment social outlook. Zeneva: International Labour Office.

Johnson, M.P., \& Schaltegger, S. (2016). Two decades of sustainability management tools for SMEs: How far have we come? Journal of Small Business Management, 54 (2), 481-505.

London Stock Exchange (2019, October). London Stock Exchange launches Green Economy Mark and Sustainable Bond Market. Retrieved June 3-18, 2021, from https://www.lseg.com/resources/mediacentre/press-releases/london-stock-exchangelaunches-green-economy-mark-and-sustainablebond-market

Mansfield, R. S. (1996). Building Competency Models: Approaches for HR Professionals. Human Resource Management, 35 (1), 7-18.

McLagan, P. (1997). Competencies: The Next Generation. Training \& Development, 51 (4), 40-47.

Prahalad, C.K. \& Hamel, G. (1990). The Core Competence of the Corporation. Harvard Business Review, 8 (3), 7991.

SB Bridge. (2021). South Baltic Bridge for Green Tech Future. Retrieved June 1-18, 2021, from https://sbbridge.eu/

Skorkova, Z. (2016). Competency models in public sector. Procedia - Social and Behavioral Sciences, 230 (2016), 226-234.

Trivellasa, P., \& Reklitisb, P. (2014). Leadership competencies profiles and managerial effectiveness in Greece. Procedia Economics and Finance, 9 (2014), 380 390

United Nations Environment Programme (UNEP). (2011). Towards a green economy: pathways to sustainable development and poverty eradication. Nairobi: United Nations Environment Programme

Weinert, F.E. (2001). Concept of competence: A conceptual 
clarification. In D.S. Rychen \& L.H. Salganik (Eds.), Defining and Selecting Key Competencies (pp. 4565). Seattle, WA: Hofgrefe \& Huber.

White, R.W. (1959). Motivation Reconsidered: The Concept of Competence. Psychological Review, 66 (5), 279-333.

\section{Acknowledgements}

This research was supported by the project "South Baltic Bridge - building bridges for the green technology future" (20182021), partly funded by Interreg South Baltic program (European Regional Development Fund). 